\title{
Development and validation of the parent-reported drug hypersensitivity quality of life questionnaire
}

\author{
Department of Pediatrics, Faculty of Medicine, Prince of Songkla University, Songkhla, Thailand
}

\section{KeY wORDS \\ drug hypersensitivity; parent-reported; quality of life; allergy; well-being}

\author{
Corresponding author \\ Araya Yuenyongviwat \\ Department of Pediatrics, \\ Faculty of Medicine \\ Prince of Songkla University, Hat Yai \\ Songkhla 90110, Thailand \\ Phone: +6674429618 \\ Fax: +6674212912 \\ E-mail: taraya@medicine.psu.ac.th
}

Doi

10.23822/EurAnnACI.1764-1489.115

\begin{abstract}
Summary
Background. Drug hypersensitivity in children impacts the quality of life of the patients and their caregivers. Measurements of the quality of life in children are different from adults, because children cannot answer the questions. This research aimed to develop and validate the Parent-reported Drug Hypersensitivity Quality of Life Questionnaire (P-DrHy-Q). Methods. The 21-item scale was initially generated by researchers. Then, 3 experts were asked for their opinion about the scale. After adjusting the contents and language, the scale was answered by 97 caregivers. A factor analysis was carried out to select the items for the final scale, and Cronbach's alpha assessed the internal consistency. Finally, we examined the test-retest reliability in another group of 10 caregivers. Results. The 21-item scale was grouped into 6 factors. However, some factors were inappropriate. Therefore, the number of factors was reduced using a statistical analysis. The final 12-item scale included two factors: mental health and social activity. The scale had good internal consistency (Cronbach's $\alpha=0.897$ ) and the test-retest associations were $\operatorname{good}(R=0.9439 ; p<0.001)$. Conclusions. The P-DrHy-Q is the first scale for assessment to consider the interaction of biopsychosocial factors on drug allergy that includes the carer-child dyad. It shows good internal consistency and reliability. Its application might be relevant for future research, and provide clinicians and researchers with a solid tool to define which type of psychosocial support is required to provide more comprehensive care in drug hypersensitivity.
\end{abstract}

\section{Introduction}

Drug hypersensitivity is a term suggested by the Review Committee of the World Allergy Organization that refers to "objectively reproducible symptoms or signs initiated by exposure to a defined stimulus at a dose tolerated by normal persons" (1) independently of the pathogenetic mechanism. Hypersensitivity reactions to drugs affect $10 \%$ to $20 \%$ of hospitalized patients and more than $7 \%$ of the general population $(2,3)$.

Drug hypersensitivity affects not only the physical health but also the mental health and quality of life of a patient and all family members. The Drug Hypersensitivity Quality of Life Questionnaire was initially created by Baiardini I et al. (4) and the results showed good validity, internal consistency, and reliability. However, measuring the quality of life in children is different from adults. Children cannot answer the questions on their own and the measurements must rely on the answers from the caregiver. Previously, a quality of life questionnaire was established to measure the caregivers who have children with allergic disease such as asthma $(5,6)$ and food allergy $(7,8)$. To date, no questionnaire is available to measure the quality of life in caregivers who have children with drug hypersensitivity. Therefore, we aimed to develop a questionnaire for the specific burden of drug hypersensitivity from the caregiver's perspective. Our goal was to develop a tool that would capture the health-related quality of life (9) using a multi-dimensional concept to examine the impact of the health status on the quality of life of caregivers who have children with a history of drug hypersensitivity. We have named this new tool the Parent-reported Drug Hypersensitivity Quality of Life Questionnaire (P-DrHy-Q).

\section{Methods}

Ethics

Ethical approval for development and validation of this study was provided by the Office of Human Research Ethics Commit- 
tee at Prince of Songkla University. All participants gave written informed consent to participate.

\section{Item generation and validity}

The researcher, a pediatric allergist, and immunologists generated a 21-item questionnaire using the Food Allergy Quality of Life Questionnaire as a reference. Each item consisted of a visual analog scale with a $0-10$ point scale. We then asked for the opinions of three experts: a pediatric allergist and immunologist; an internal medicine allergist and immunologist; and a developmental-behavioral pediatrician. The questionnaire was adjusted by recommendation and then 97 caregivers of children under the age of 15 years with a history of drug hypersensitivity answered the P-DrHy-Q at our pediatric outpatient department. The questionnaires were collected from Oct 2016 to March 2017. After the data collection was complete, a factor analysis was done to group the questions.

\section{Reliability}

The scale homogeneity (internal consistency) was computed based on Cronbach's correlation coefficient on the extracted factors. Cronbach's alpha analysis was used for the full scales and subscales. The test-retest reliability of the P-DrHy-Q was ascertained to determine whether the questionnaire would provide the same results when used repeatedly in a stable condition. Therefore, 10 caregivers of children under the age of 15 years with a history of drug hypersensitivity answered the P-DrHy-Q two times at the pediatric wards at 3 days apart in the absence of any significant clinical or personal change. The results were analyzed by Pearson's correlation coefficient.

\section{Statistical analysis}

The data were recorded using Epidata and analyzed using R statistical software. The internal consistency of the scale was evaluated using Cronbach's alpha coefficient. It is accepted crossways that alpha $>0.7$ is acceptable, $>0.8$ is good, and $>0.9$ is excellent. It was acceptable at a loading level greater than 0.5 . Pearson's correlation coefficient test was performed to assess the discriminative reliability of the test-retest associations.

\section{Results}

\section{Item generation and validity}

The researchers generated a 21-item questionnaire. After obtaining the opinions from the experts, the questionnaire was adjusted. The adjusted questionnaire was applied in 97 caregivers of children under 15 years of age with a history of drug hypersensitivity at the pediatric outpatient department. The demographic characteristics of the participants are summarized in table I. After the data collection, 21 items were included in the factor analysis. Varimax factor rotation was undertaken and only factors that were more than 0.50 were considered for the analysis. Six components were extracted using the principal component analysis. However, due to item distribution, the analysis was forced into two factors and each of the items had a loading level greater than 0.50 . The final version of the

Table I - Demographics for participants in validate phase $(n=97)$.

\begin{tabular}{|c|c|}
\hline Sex female, number (\%) & $84(86.6)$ \\
\hline Current age (yr), median (range) & $39.1(22.3-72.4)$ \\
\hline $\begin{array}{l}\text { Main caregiver, number }(\%) \\
\text { father } \\
\text { mother } \\
\text { other }\end{array}$ & $\begin{array}{l}13(13.4) \\
76(78.4) \\
8(8.2)\end{array}$ \\
\hline $\begin{array}{l}\text { Informative caregiver, number (\%) } \\
\text { father } \\
\text { mother } \\
\text { other }\end{array}$ & $\begin{array}{l}14(14.4) \\
79(81.4) \\
4(4.1)\end{array}$ \\
\hline $\begin{array}{l}\text { Marital status, number }(\%) \\
\text { living with partner } \geq 6 \mathrm{mo} / \mathrm{yr} \\
\text { living with partner }<6 \mathrm{mo} / \mathrm{yr} \\
\text { devoid } \\
\text { widow }\end{array}$ & $\begin{array}{l}86(88.7) \\
4(4.1) \\
3(3.1) \\
2(2.1)\end{array}$ \\
\hline $\begin{array}{l}\text { Occupation, number (\%) } \\
\text { government officer } \\
\text { state enterprise } \\
\text { owner } \\
\text { officer } \\
\text { homemaker } \\
\text { freelance }\end{array}$ & $\begin{array}{l}27(27.8) \\
4(4.1) \\
8(8.2) \\
15(15.5) \\
16(16.5) \\
27(27.8)\end{array}$ \\
\hline $\begin{array}{l}\text { Education, number }(\%) \\
\text { primary school } \\
\text { high school } \\
\text { certificate } \\
\text { bachelor } \\
\text { master/PhD }\end{array}$ & $\begin{array}{l}7(7.2) \\
16(16.5) \\
10(10.3) \\
53(54.6) \\
11(11.3\end{array}$ \\
\hline $\begin{array}{l}\text { Number of children within family, } \\
\text { number }(\%) \\
1-2 \text { persons } \\
3-4 \text { persons } \\
>5 \text { persons }\end{array}$ & $\begin{array}{l}74(76.3) \\
23(23.7) \\
0\end{array}$ \\
\hline $\begin{array}{l}\text { Family income Baht/month, number (\%) } \\
<15000 \\
15000-50000 \\
50000-100000 \\
>100000\end{array}$ & $\begin{array}{l}31(32.0) \\
49(50.5) \\
14(14.4) \\
3(3.1)\end{array}$ \\
\hline $\begin{array}{l}\text { Experienced in care children with history } \\
\text { of drug hypersensitivity before, number } \\
(\%) \\
\text { no } \\
\text { yes }\end{array}$ & $\begin{array}{l}62(63.9) \\
35(36.1)\end{array}$ \\
\hline
\end{tabular}


Figure 1 - Parent-reported drug hypersensitivity quality of life questionnaire (P-DrHy-Q).

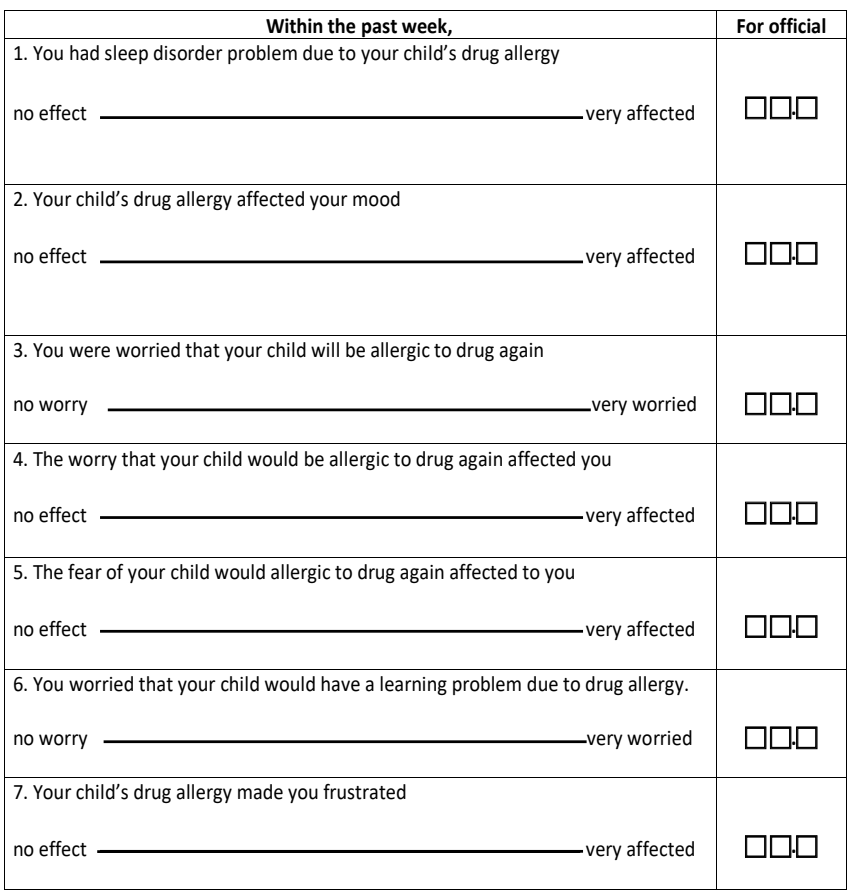

P-DrHy-Q (figure 1) consisted of 12 items distributed into two factors: mental health and social activity (table II).

\section{Reliability}

Cronbach's alpha coefficient for the P-DrHy-Q was 0.897 which indicated good internal consistency between the individual ques-

\begin{tabular}{|l|c|}
\hline \multicolumn{1}{|c|}{ Within the past week, } & For official \\
\hline 8. You needed to take care of your child more than usual when you go out. & \\
\hline $\begin{array}{l}\text { 9. Your child's drug allergy made you lack the time for leisure activities (exercise, } \\
\text { movie, eating out). }\end{array}$ & \\
no effect & $\square$ \\
\hline $\begin{array}{l}\text { 10. Your child's drug allergy caused your child felt discriminated from another } \\
\text { child. }\end{array}$ & \\
no effect & \\
\hline 11. Your child's drug allergy affected your family budget & \\
no effect & \\
\hline 12. Your child's drug allergy affected your social interactions very affected & \\
no effect & \\
\hline
\end{tabular}

tions in the instrument. The alphas for all subscales are shown in table III. To determine the test-retest reliability of the P-DrHy-Q, 10 caregivers of children under 15 years of age with a history of drug hypersensitivity answered the questionnaire two times at the pediatric wards at 3 days apart. During this period no change in the child's drug hypersensitivity was expected. Pearson's correlation coefficient was $0.94(\mathrm{p}<0.01)$ which indicated excellent reliability.

Table II - Factor analysis and loadings.

\begin{tabular}{|c|c|c|}
\hline Item (abbreviated wording) & mental health loading & social activity loading \\
\hline developed sleep disorder & 0.50 & \\
\hline impacted your mood & 0.50 & \\
\hline worried that your child being allergic to drug again affects you & 0.82 & \\
\hline fear that child being allergic to drug again affects you & 0.71 & \\
\hline when you go out you need to take care more than usual & & 0.52 \\
\hline lack of time for leisure (exercise, movie, eating out) & & 0.74 \\
\hline felt discriminated from another child & & 0.71 \\
\hline your family budget is affected & & 0.69 \\
\hline
\end{tabular}


Table III - Cronbach's alphas for the P-DrHy-Q and subscales.

\begin{tabular}{lc}
\hline P-DrHy-Q & Cronbach's alphas \\
\hline Total scale & 0.8974 \\
\hline Subscales & \\
mental health & 0.8735 \\
social activity & 0.8424 \\
\hline
\end{tabular}

\section{Discussion}

The results of the study showed that the P-DrHy-Q is a self-applied psychosocial impact scale in drug allergy. Furthermore, it is a brief and low-cost way to assemble data that may guide the clinician to decide which factors should be included in a multidisciplinary approach to their patients.

The strength of this study is that this is the first scale in drug allergy that focuses on the carer-child dyad. This scale showed good internal consistency and reliability. The factor analysis demonstrated that the scale may be used to measure two types of parental burden: mental health and social activity. Both of these domains had very good internal reliability in both versions of the scale. Therefore, it may be possible to adapt the

\section{References}

1. Johansson SG, Bieber T, Dahl R, Friedmann PS, Lanier BQ, Lockey RF, et al. Revised nomenclature for allergy for global use: report of the Nomenclature Review Committee of the World Allergy Organization, October 2003. J Allergy Clin Immunol 2004; 113:832-836.

2. Guglielmi L, Guglielmi P, Demoly P. Drug hypersensitivity: epidemiology and risk factors. Curr Pharm Des 2006; 12:3309-3312.

3. Romano A, Demoly P. Recent advances in the diagnosis of drug allergy.Curr Opin Allergy Clin Immunol 2007; 7:299-303.

4. Baiardini I, Braido F, Fassio O, Calia R, Canonica GW, Romano A, et al. Development and validation of the Drug Hypersensitivity Quality of Life Questionnaire. Ann Allergy Asthma Immunol 2011; 106:330-335.

5. Juniper EF, Guyatt GH, Feeny DH, Ferrie PJ, Griffith LE, Townsend M. Measuring quality in the parents of children with asthma. Qual Life Res 1996; 5:27-34. scale to incorporate two sub-scale scores as well as an overall score to provide more information on the type of parental burden that is most salient. A limitation of the study was that it was done in a single center that possibly did not include all of the patients with different types of drug allergy.

\section{Conclusions}

This is the first parent-reported health-related quality of life instrument for drug allergy. This study demonstrated that the $\mathrm{P}-\mathrm{DrHy}-\mathrm{Q}$ is reliable and valid for a Thai population. Factor analysis revealed two distinct domains: mental health and social activity. Gaining information on which type of parental burden is more salient and may be useful in determining appropriate support for the caregivers. A further study to evaluate other psychometric properties is essential.

\section{Conflict of interests}

The authors declare that they have no conflict of interests.

\section{Acknowledgments}

This study was funded by the Faculty of Medicine, Prince of Songkla University, Songkhla, Thailand.

6. Stelmach I, Podlecka D, Smejda K, Majak P, Jerzyńska J, Stelmach $\mathrm{R}$, et al. Pediatric Asthma Caregiver's Quality of Life Questionnaire is a useful tool for monitoring asthma in children. Qual Life Res 2012; 21:1639-1642.

7. Cohen BL, Noone S, Munoz-Furlong A, Sicherer SH. Development of a questionnaire to measure quality of life in families with a child with food allergy. J Allergy Clin Immunol 2004; 114 (5):1159-1163.

8. Cortes A, Castillo A, Sciaraffia A. Development of the scale of psychosocial factor in food allergy (SPS-FA). Pediatr Allergy Immunol 2013; 24:671-677.

9. Yin S, Njai R, Barker L, Siegel PZ, Liao Y. Summarizing health-related quality of life (HRQOL): development and testing of a one-factor model. Popul Health Metr 2016; 14:22. 